\title{
Von Baum zu Baum
}

\section{Erhard Taverna}

Dr. med., Mitglied der Redaktion

Es war einmal eine Familie mit Haus und Garten mit vielen Hecken und Vögeln. Zu jeder Adventszeit kam der Tag, an dem ein Weihnachtsbaum, eingerollt in ein Netz, im Holzschopf auf seinen Auftritt wartete. Gross war jeweils die Auslese auf dem Forstamt der Gemeinde oder beim Bauern, der mit seiner Plantage einen Zustupf verdiente. Am Vortag der Familienzusammenkunft wurde der Baumstamm in ein Wassergefäss gestellt und mit Zwingen festgeschraubt. Das Schmücken war ein gemeinsames Ritual. Salzteigfigürchen, handgesägte Schaukelpferdchen, farbige Vögel, Glas- und hauchdünne, farbige Kugeln. Und natürlich die gut gelagerten Bienenwachskerzen. Unter dem Baum Tannenzweige und viel Platz für Geschenkpakete. Im neuen Jahr brannten die Kerzenreste noch einmal bis auf kleine Stumpen, dann wurde der Schmuck sorgfältig in Kartonschachteln versorgt, und der Baum steckte im Schnee, bis er im Frühjahr für das Kaminfeuer zersägt wurde.

Das war einmal vor langer Zeit.

Heute leben Enkel und Urenkel über alle Kontinente verstreut und sind pausenlos beschäftigt. Die Urgrosseltern sind trotz vieler Gelenkimplantate nicht mehr so beweglich wie früher. Verschiedene Hauslieferdienste ermöglichen ihnen aber immer noch ein Leben in den eigenen vier Wänden. Um den weitläufigen Garten kümmern sich die Gärtner. Von der echten Nordmannstanne haben sie schon vor langem auf einen künstlichen Baum umgestellt. Das hat enorm viele Vorteile. Wären sie nur schon früher darauf gekommen. Keine Harzflecken auf dem Teppich, keine

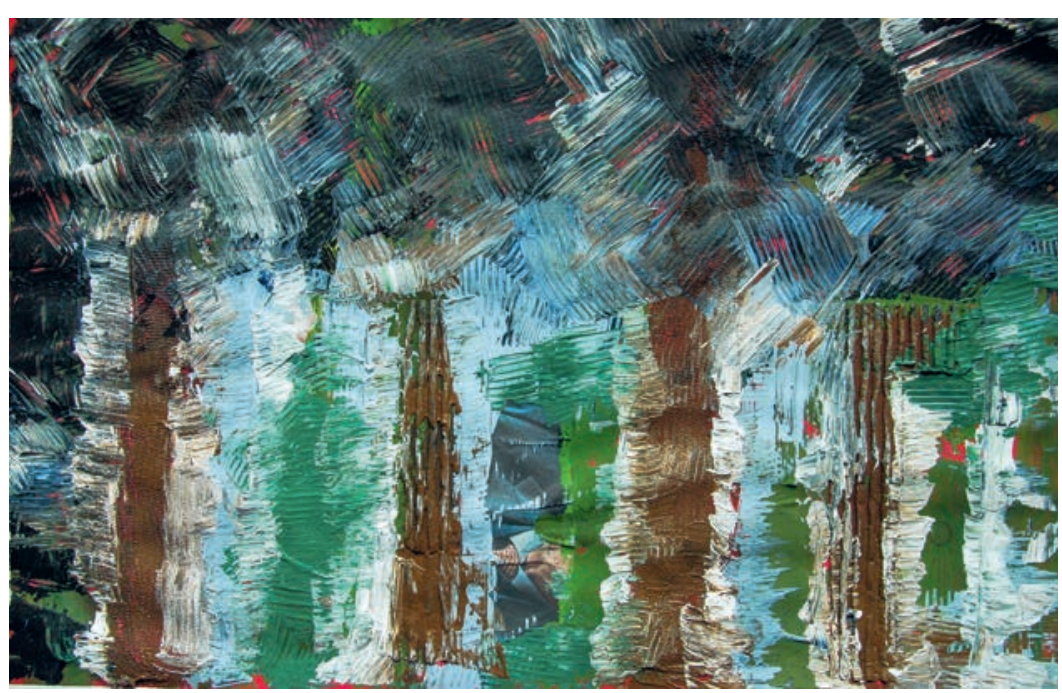

Nadeln, die den Staubsauger verstopfen, keine Brandgefahr. Das Bäumchen liegt zusammengefaltet, staubgeschützt in der mitgelieferten Tasche. Eine PremiumDouglasie mit einem Innenstamm aus Metall und symmetrisch angeordneten Spritzgusszweigen, Polyethylenabdrucken echter Triebe, säuberlich ausgegossen und von Hand befestigt. Eingebaute LED-Lämpchen sorgen für ein sanftes Licht. Mit den künstlichen Schneeflocken ist der neue Baum schöner als alle seine Vorgänger. Einmal an der Steckdose, ist alles mit Fernbedienung regulierbar. Das Dimmen der Lichter, der Farbwechsel, die langsame Drehung der Baumpyramide und die Wahl der Weihnachtslieder, die aus der Halterung ertönen. Dank Duftspray riecht es wunderbar nach frischem Tannengrün.

Das war einmal vor langer Zeit.

Dank modernster Medizintechnik lebt es sich sehr angenehm. Körpersensoren regeln die vielen Schläuche und Sonden, die alles Nötige zu- und abführen. Es ist nicht mehr nötig, die Wohnzelle im vierzigsten Stock zu verlassen. Ein Pflegeroboter sorgt rund um die Uhr für das Wohl der Alten. Der Neubau, wo einst ein Garten war, überragt das eigene Haus um weitere zehn Stockwerke. Alle Nachkommen haben als 3-D-Hologramme frohe Weihnachten gewünscht. Eine lange ermüdende Reihe. Trotz Hirnstimulation ist es nicht mehr möglich, sich alle ihre Gesichter und Namen zu merken. Das Schönste aber ist die neue VR-Brille, die nach der letzten Staroperation implantiert wurde. Was wäre das Leben ohne die elektronischen Vorsorgetipps des Hausarztes. Heute erscheint das perfekte stereoskopische Bild eines wunderschönen Weihnachtsbaumes. Eine wahre Pracht mit viel funkelnder Lametta, wunderschönem Kerzenlicht und himmlischen Chorälen. Weissgewandete Engel spielen auf Harfen und Zimbeln. Ein gut gelaunter Nikolaus stapelt die digitalen Geschenkpäckchen der Ur-Ur-Ur-Enkel rund um den Baum. Fortschritt sei Dank geschieht auf jedem Stockwerk dasselbe. Alle feiern das Google-gesponserte Weihnachtskaraoke. Dank Playback singen Greise und Greisinnen mit jugendlicher Stimme «O du fröhliche Weihnachtszeit». In dieser hochheiligen Nacht ein Hochhaus des Friedens und der Harmonie. Das war einmal vor langer Zeit. 